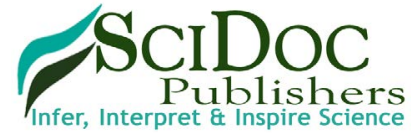

\section{Surface Property Dependent Biocompatibility Analysis of NiTi Shape Memory Alloys to be used in Root Canal Shaping Applications}

Research Article

S Mine Toker

Metallurgical and Materials Engineering Department, Eskisehir Osmangazi University, Eskisehir, Turkey.

\title{
Abstract
}

Aim: The current study aimed to evaluate the biocompatibility of NiTi SMAs, to be used as root canal shaping instrument materials, in relation to their surface properties.

Material and Methods: NiTi SMA samples with different surface properties were subjected to ex situ and in vitro biocompatibility tests following their initial structural analysis via SEM and profilometer. For the $e x$ situ tests, the samples were statically immersed in AS for 24 hours and their surfaces were examined via SEM. For the in vitro analysis, fibroblast cells were seeded on the samples for 24 hours, which were then fixated on the sample surfaces and examined with SEM in terms of their attachment behavior and morphologies. The numbers of viable cells on each sample were also counted with Cellometer.

Results: The NiTi SMA sample with lower roughness values exhibited better biocompatibility in both ex situ and in vitro tests with lower corrosion product deposition and increased cell viability.

Conclusion: Among the tested samples, the NiTi SMA sample with lower surface roughness constitutes a better alternative as a root canal shaping instrument material.

Keywords: Root-Canal-Shaping; Rotary-File; Nickel-Titanium; Surface; Biocompatibility.

Abbreviations: Nickel Titanium (NiTi), Shape Memory Alloys (SMAs), Scanning Electron Microscopy (SEM), Artificial Saliva (AS).

\section{Introduction}

Root canal shaping is a complicated dental application which requires special instrumentation, specifically rotary files for the removal of existing nerves in tooth $[1,2]$. As root canal shaping instruments, metallic materials are preferred mainly owing to their mechanical properties. Conventional metals such as stainless steels have been used over the years due to their non-corrosive properties in addition to their mechanical durability $[3,4]$. However, recently, NiTi alloys SMAs have come into picture as an alternative material in root canal therapy. NiTi SMAs provide an advantage over stainless steel with their high ability to maneuver during the canal shaping procedure, owing to their superelastic properties $[3,4]$.

Shape memory and superelastic properties of NiTi SMAs have made them widely used materials for many biomedical purposes including dental applications such as dental implants, orthodontic archwires and root canal instruments [1-4]. Although NiTi SMAs have been widely used for various biomedical applications owing to their shape memory properties and pseudoelasticity, the potential Ni release and corrosion product deposition when the alloy is exposed body fluids or contacts the tissue, still makes the biocompatibility analysis of these alloys critical for ensuring their safe use in biomedical application [5-8]. Especially dental biomaterials are subjected to a very aggressive environment due to the low $\mathrm{pH}$ of the saliva and the various chemicals present within the saliva and the material may come across according to the different nutritional habits [7,8]. Therefore, it is essential evaluate the biocompatibility of NiTi SMAs intended for dental applications, including root canal instruments.

As in all biomaterials, biocompatibility of NiTi SMAs is dependent on both the response of the surrounding tissue to the alloy, and

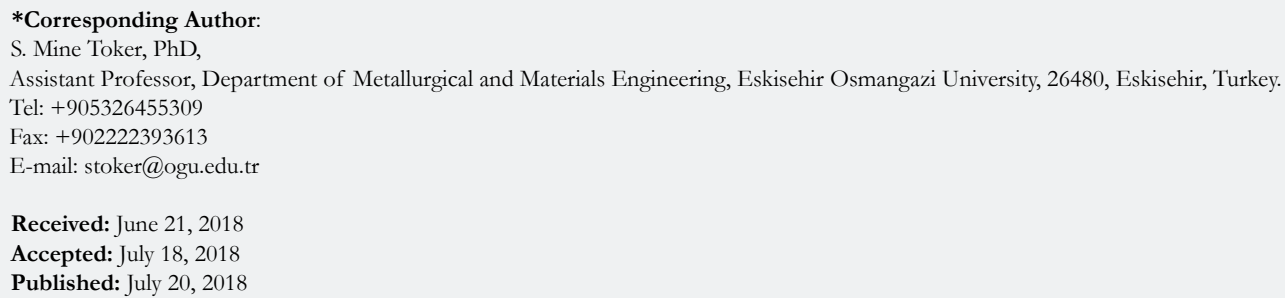

Copyright: S Mine Toker ${ }^{\circ}$ 2018. This is an open-access article distributed under the terms of the Creative Commons Attribution License, which permits unrestricted use, distribution and reproduction in any medium, provided the original author and source are credited. 
the alloy's reaction to the body fluid or tissue of contact [6-8]. Moreover, the alloy's response to the physiological environment is influenced by various material properties, including its chemical content, microstructure and surface characteristics $[9,10]$. Among these, surface characteristics constitute a critical parameter in determining biocompatibility, as the first biomaterial-tissue interaction takes place on the surface. And for metallic materials, including NiTi SMAs, surface properties are strongly related to the processing history applied to obtain certain geometries and therefore the geometry of the sample [6].

With this motivation, the current study aims to analyze the biocompatibility of NiTi SMAs intended for root canal shaping applications, in relation to their surface characteristics. Specifically, effect of surface roughness and groove properties on the biocompatibility of NiTi SMAs were investigated through ex situ and in vitro experiments.

\section{Materials \& Methods}

Two sets of cylindrical NiTi SMAs with different cross-sectional radii, (referred to as thick wire: $r=1.75 \mathrm{~mm}$ and thin wire: $r=1 \mathrm{~mm}$ ) therefore with different geometries, were tested through ex situ and in vitro experiments. Chemical content, geometry and surface roughness information of the NiTi samples used in the experiments are provided in Table-1. For the ex situ experiments, the samples were statically immersed in AS solution, for which the chemical content information is provided in Table- 2 , at $37^{\circ} \mathrm{C}$ for 24 hours. A low $\mathrm{pH}$ of 2.3 was preferred in order to simulate the more aggressive conditions that may possibly be created with nutritional habits. Following the immersion, the samples were investigated with scanning electron microscopy (SEM) to observe the structural changes and possible corrosion product deposition that occurred on the surface during the immersion.

The NiTi samples were also subjected to in vitro tests in order to observe the cell response on the two different surfaces. 3T3 fibroblast cells were seeded on the two sets of NiTi samples and incubated for 24 hours. Following the incubation, the cells were fixated on the sample surfaces and investigated via SEM in order to observe the cell attachment and proliferation behavior as well as cell morphology. The number of attached cells per millimeter on both samples were also counted. For cell counting, samples were removed from cell culture media and rinsed in phosphatebuffered saline. After rinsing, a Trypsin-EDTA solution was applied to the samples for the removal of the attached cells and the obtained solutions were analyzed for the number of attached cells per milliliters via a Cellometer cell counter.
The reason for choosing 24 hours as the static immersion and incubation period was to provide a testing environment consistent with the application. Since the root canal instruments contact the tissues and bodily fluids for a limited amount of time, 24 hours were considered suitable and sufficient to stimulate the actual conditions.

Prior to the static immersion and in vitro experiments, the NiTi samples were also examined in their as-is conditions with SEM and profilometer, for the observation of the existing structural features and measurement of the average surface roughness $(R$ in $\mu \mathrm{m})$. The measured roughness values are also provided in Table-1.

\section{Results and Discussion}

The SEM images of the thin and thick wire sample surfaces in their as received condition are provided in Figure 1. This initial SEM analysis demonstrated that the two sample surfaces have significantly different properties at the micron scale, especially in terms of the surface groove characteristics and depth. This qualitative observation was also supported by the quantitative profilometer analysis which provided information about the surface roughness of the two samples. The roughness measurements of the samples have shown that, thin wire $\left(R_{a} 0.7\right.$ $\mu \mathrm{m})$ exhibits a rougher surface as compared to thick wire $\left(\mathrm{R}_{\mathrm{a}}{ }^{\mathrm{a}} .45\right.$ $\mu \mathrm{m})$ (Table-1).

SEM investigations of the thin and thick wire samples following the immersion exhibited significant differences in terms of both new structure formation in AS (Figure-2). Specifically, thin wire surface was observed to be widely covered with corrosion products (the darker structures prevalent in Figure 2-a), which deposited from the AS solution during immersion. On the other hand, the prevalence of corrosion products on the thick wire surface were much lower, both in quantity and in terms of spreading (Figure 2-b). This behavior was attributed to the higher surface energy levels resulting from the higher roughness of the thin wire surface, which provides a more favorable environment for new product deposition. While for some biomaterials such as dental implants, a higher energy surface which may promote tissue growth may be an advantage, for root canal instruments new structure deposition would be a disadvantage which may impede the maneuverability of the metal within the tissue during the later stages of the root canal shaping procedure. Therefore, the initial static immersion experiment results revealed that the relatively smoother thick wire surface would be a better alternative for the root canal shaping rotary files.

Figure 1. SEM images of the sample surfaces in their as received conditions: a) thin wire b) thick wire.

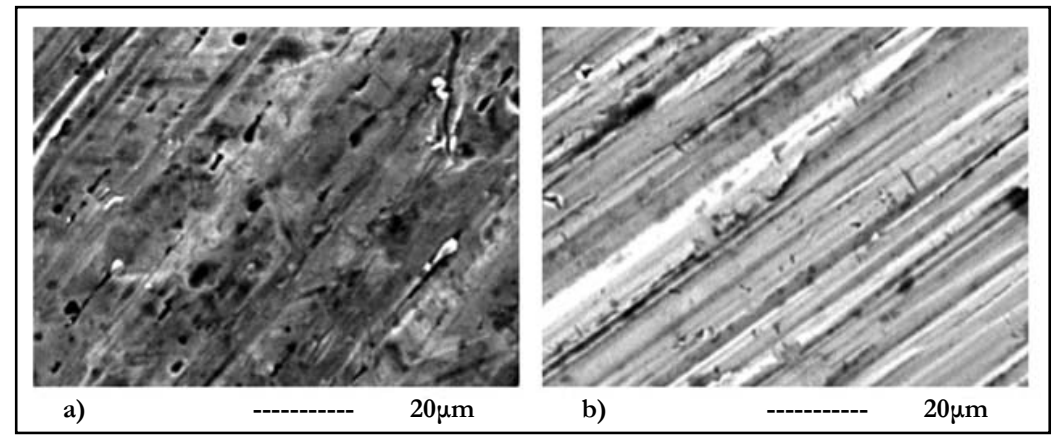

S Mine Toker. Surface Property Dependent Biocompatibility Analysis of NiTi Shape Memory Alloys to be used in Root Canal Shaping Applications. Int J Dentistry Oral Sci. 
Table 1. Chemical content, geometry and surface roughness information of the NiTi samples.

\begin{tabular}{|c|c|c|c|c|}
\hline Sample Name & Ni content (at. \%) & Sample Height $\mathbf{( c m )}$ & Sample Radius $\mathbf{( m m )}$ & Surface Roughness $\left(\mathbf{R}_{\mathbf{a}} \boldsymbol{\mu m}\right)$ \\
\hline Thin wire & 50.4 & 2.75 & 1 & $0.70 \pm 0.11$ \\
\hline Thick wire & 50.7 & 1.5 & 1.75 & $0.45 \pm 0.06$ \\
\hline
\end{tabular}

Table 2. Chemical content of the artificial saliva solution (pH: 2.3) used in the static immersion experiments.

\begin{tabular}{|c|c|}
\hline Ingredients & Amount (g/1) \\
\hline $\mathrm{NaCl}$ & 0.4 \\
\hline $\mathrm{KCl}$ & 0.4 \\
\hline $\mathrm{CaCl}_{2} .2 \mathrm{H}_{2} \mathrm{O}$ & 0.906 \\
\hline $\mathrm{NaH}_{2} \mathrm{PO}_{4} \cdot 2 \mathrm{H}_{2} \mathrm{O}$ & 0.690 \\
\hline Urea & 1 \\
\hline
\end{tabular}

Figure 2. SEM images of the sample surfaces following 24 hours of static immersion in artificial saliva: a) thin wire b) thick wire.

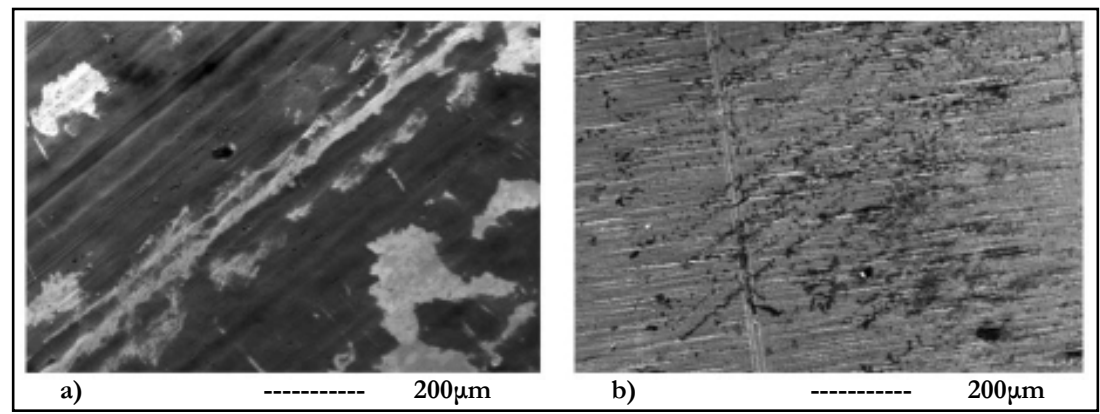

Figure 3. SEM images of the sample surfaces following 24 hours of incubation with fibroblast cells: a) thin wire b) thick wire.

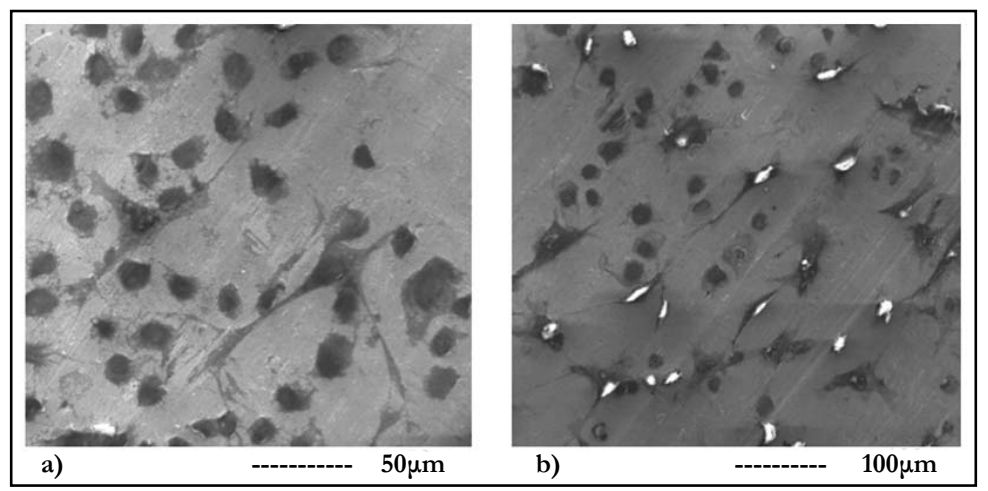

Figure 4. Number of attached cells per milliliter $(\mathrm{mL})$ on the samples following 24 hours of incubation with fibroblast cells.

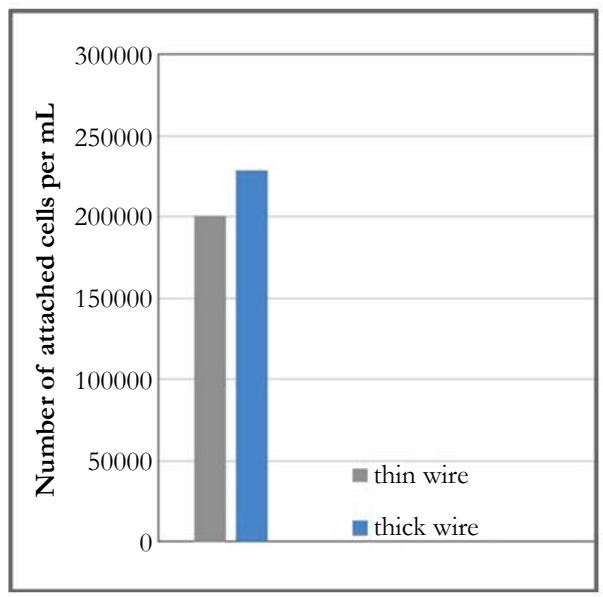


For a more thorough biocompatibility analysis, the samples were also subjected to in vitro tests with fibroblast cells, in order to investigate the cell attachment and viability behavior on the two different surfaces. SEM images of the fibroblast cells fixated on the thin and thick wire surfaces following 24 hours of incubation exhibited that, both sample surfaces were favorable for cell attachment (Figure-3). Specifically, the fibroblast cells were observed to attach and show tendencies of spreading even after 24 hours on both surfaces (Figure 3-a, b). Moreover, there weren't any significant differences in terms of cell morphologies or attachment behaviors on the thin and thick wire surfaces following 24 hours of incubation, which may be considered a preliminary and positive indication of the biocompatibilities of both surfaces. These qualitative observations were followed by a quantitative analysis on cell viability, which provided information about the number of cells per milliliter on each sample after 24 hours of incubation. The results of the cell count experiment (Figure-4) revealed that, the number of attached cells on the thick wire surface were higher as compared the that on the thin wire surface. Normally, the rougher surface of the thin wire with higher surface energy may be expected to be more favorable for cell attachment. However, in the case of NiTi, the increased reactivity created with higher surface energy may also lead to an increased Ni release during exposure to bodily fluids. Therefore, the relatively lower cell viability on the rougher thin wire surface can be explained by the potentially increased levels of $\mathrm{Ni}$ in the cell culture media, which would be toxic for the cells. Therefore, thick wire sample would provide a better alternative for root canal instruments also in terms of its relatively more compatible surface for cell viability.

Overall, the results of the 24-hour ex situ and in vitro biocompatibility tests have demonstrated that, for the root canal instruments, increased surface roughness provides disadvantages in terms of corrosion product deposition, potential $\mathrm{Ni}$ release and thereby cell viability. Therefore, among the tested samples, thick wire sample with lower surface roughness constitutes a better alternative as a root canal shaping rotary file material.

\section{Conclusion}

Two types of NiTi SMA samples intended as root canal shaping materials, with different surface properties, were tested in terms of their biocompatibility through ex situ and in vitro tests. Results of the 24-hour analysis revealed that, among the tested samples, the thick wire sample which demonstrated lower surface roughness constitutes a more biocompatible alternative as a root canal shaping rotary file material with its improved cell viability and lower corrosion product deposition.

\section{References}

[1]. Thompson SA. An overview of nickel-titanium alloys used in dentistry. Int Endod J. 2000 Jul;33(4):297-310. PubMed PMID: 11307203.

[2]. Ounsi HF, Nassif W, Grandini S, Salameh Z, Neelakantan P, Anil S. Evolution of Nickel-titanium Alloys in Endodontics. J Contemp Dent Pract. 2017 Nov 1;18(11):1090-1096. PubMed PMID: 29109327.

[3]. Carvalho A, Montalvão D, Freitas M, Reis L, Fonte M. Determination of the rotary fatigue life of NiTi alloy wires. Theore Appl Fract Mech. 2016 Oct 1;85:37-44.

[4]. D'Amario M, De Angelis F, Mancino M, Frascaria M, Capogreco M, D'Arcangelo C. Canal shaping of different single-file systems in curved root canals. Int J Dent Sci. 2017 Dec 1;12(4):328-32.

[5]. Baumann MA. Nickel-titanium: options and challenges. Dent Clin North Am. 2004 Jan;48(1):55-67. PubMed PMID: 15066507.

[6]. Toker SM, Canadinc D, Maier HJ, Birer O. Evaluation of passive oxide layer formation-biocompatibility relationship in NiTi shape memory alloys: geometry and body location dependency. Mater Sci Eng C Mater Biol Appl. 2014 Mar 1;36:118-29. doi: 10.1016/j.msec.2013.11.040. PubMed PMID: 24433894.

[7]. Toker SM, Canadinc D. Evaluation of the biocompatibility of NiTi dental wires: a comparison of laboratory experiments and clinical conditions. Mater Sci Eng C Mater Biol Appl. 2014 Jul 1;40:142-7. doi: 10.1016/j. msec.2014.03.060. PubMed PMID: 24857476.

[8]. Uzer B, Gumus B, Toker SM, Sahbazoglu D, Saher D, Yildirim C, et al. A critical approach to the biocompatibility testing of NiTi orthodontic archwires. Int J Metall Met Phys. 2016;1(003).

[9]. Uzer B, Toker SM, Cingoz A, Bagci-Onder T, Gerstein G, Maier HJ, et al. An exploration of plastic deformation dependence of cell viability and adhesion in metallic implant materials. J Mech Behav Biomed Mater. 2016 Jul;60:177-186. doi: 10.1016/j.jmbbm.2016.01.001. PubMed PMID: 26807771 .

[10]. Toker SM, Gerstein G, Maier HJ, Canadinc D. Effects of microstructural mechanisms on the localized oxidation behavior of NiTi shape memory alloys in simulated body fluid. Int J Mater Sci. 2018 Jan 1;53(2):948-58.

Special Issue on

"Dental Biomaterials Tools \& Techniques"

Theme Edited by:

S. Mine Toker,

Eskisehir Osmangazi University, Turkey.

E-mail: stoker@ogu.edu.tr 